\title{
OS ELEMENTOS PARA O DESENVOLVIMENTO DE UM REGIME TRANSNACIONAL SUSTENTÁVEL DE PROTEÇÃO JURÍDICA DOS CONHECIMENTOS TRADICIONAIS ASSOCIADOS À BIODIVERSIDADE AMAZÔNICA
}

Ana Carolina Couto Matheus ${ }^{1}$

Recebido em 25/07/2019

Aceito em 03/08/2021

\begin{abstract}
RESUMO
O objeto do trabalho em testilha é a possibilidade da criação de elementos para o desenvolvimento de um regime transnacional sustentável de proteção jurídica dos conhecimentos tradicionais associados à biodiversidade amazônica, considerando a imprescindível inter-relação dos conhecimentos tradicionais dos povos da Amazônia com a sustentabilidade. Comporta necessariamente um tratamento transdisciplinar, pois as categorias de construções da realidade são diversas, e, embora diferentes, encontram-se profundamente interligadas ou interdependentes. O método utilizado na fase de investigação e na fase de tratamento dos dados foi o indutivo. Nas diversas fases da pesquisa foram acionadas as técnicas do referente, da categoria, do conceito operacional, da pesquisa bibliográfica e do fichamento. O desenvolvimento do tema pautou-se pela persecução dos objetivos geral e específicos que nortearam a produção. O relatório se encerra com as conclusões e consubstancia o resultado de todos os achados da pesquisa acadêmica, findando por confirmar a hipótese inicialmente concebida, tendo, alfim, alcançado os elementos para o desenvolvimento de um regime transnacional sustentável de proteção jurídica dos conhecimentos tradicionais associados à biodiversidade amazônica.
\end{abstract}

PALAVRAS CHAVE: Conhecimentos Tradicionais Associados à Biodiversidade Amazônica. Elementos. Regime Transnacional de Proteção Jurídica. Sustentabilidade.

\section{THE ELEMENTS FOR THE DEVELOPMENT OF A SUSTAINABLE}

\section{TRANSNATIONAL LEGAL PROTECTION REGIME OF TRADITIONAL}

\section{KNOWLEDGE ASSOCIATED WITH AMAZON BIODIVERSITY}

ABSTRACT

The object of this work is the possibility of creating elements for the development of a sustainable transnational regime of legal protection of the traditional knowledge associated with the Amazonian biodiversity, considering the indispensable interrelation between the traditional knowledge of the Amazonian peoples and sustainability. It necessarily entails transdisciplinary treatment, since the categories of constructions of reality are diverse, and although different, they are deeply interconnected or

\footnotetext{
${ }^{1}$ Doutora em Ciência Jurídica pela UNIVALI-SC. Mestre em Direito pela UNIPAR-PR. Especialista em Direito Tributário pela UnP-RN. Pós-graduada em Direito Constitucional pela UVB-SP. Graduada em Direito pela TOLEDO-SP. Professora Adjunta III do CCJSA da UFAC-AC. Coordenadora do Núcleo de Prática Jurídica e Estágios. Professora da Pós-Graduação. Orientadora. Conferencista. Conselheira Editorial. Pesquisadora. Advogada. Consultora Jurídica. E-mail: carolcoutomatheus@ @otmail.com.
} 
interdependent. The method used in the research phase and in the data processing phase was inductive. In the various phases of the research the techniques of referent, category, operational concept, bibliographic research and file were used. The development of the theme was guided by the pursuit of the general and specific objectives that guided the production. The report concludes with the conclusions and substantiates the results of all the findings of the academic research, and finally confirms the hypothesis initially conceived, having finally reached the elements for the development of a sustainable transnational legal protection regime of the traditional knowledge associated with amazonian biodiversity.

Keywords: Traditional Knowledge Associated with Amazon Biodiversity. Elements. Transnational Legal Protection Regime. Sustainability

\section{INTRODUÇÃO}

Considerando a imprescindível inter-relação dos conhecimentos tradicionais dos povos da Amazônia com a sustentabilidade, o objeto basilar do trabalho em epígrafe é a possibilidade da criação de elementos para o desenvolvimento de um regime transnacional sustentável de proteção jurídica dos conhecimentos tradicionais associados à biodiversidade amazônica.

A escolha do tema justifica-se em razão da importância e complexidade. Comporta necessariamente um tratamento transdisciplinar, uma vez que as categorias de construções da realidade são diversas, e, embora diferentes, encontram-se profundamente interligadas ou interdependentes.

Assim posto, o problema da pesquisa em testilha é criar os elementos para o desenvolvimento de um regime transnacional sustentável de proteção jurídica dos conhecimentos tradicionais associados à biodiversidade amazônica, tendo em vista a amplitude do tema e a necessidade de melhorar a proteção jurídica destes importantes conhecimentos geracionais. O aludido problema concentra seus esforços na busca de substituir o sistema de patentes, bem como o sistema de garantia dos direitos de autor, inadequados para proteger as comunidades tradicionais.

Todo trabalho encontra-se parametrizado teoricamente na Constituição Federal de 1988, na legislação nacional e estrangeira, em vasta literatura nacional e estrangeira, artigos de revistas jurídicas especializadas e jurisprudência pertinente ao tema.

Para o equacionamento do problema suscita-se a seguinte hipótese, a saber: a floresta amazônica está inserida além do Brasil, em territórios de outros países sul-americanos como a Bolívia, a Colômbia, o Equador, as Guianas, o Peru, o Suriname e a Venezuela, portanto, sua conservação exige, necessariamente, o compromisso e a organização de todos esses países. O trabalho investiga juridicamente se existe a possibilidade de, neste cenário transnacional, criar 
os elementos para o desenvolvimento de um regime transnacional de proteção jurídica dos conhecimentos tradicionais e exercer a tutela sustentável dos conhecimentos tradicionais associados à biodiversidade amazônica.

Em função da problemática e da hipótese, o objetivo geral do trabalho consiste em analisar a possibilidade de criar elementos para o desenvolvimento de um regime transnacional sustentável de proteção jurídica dos conhecimentos tradicionais associados à biodiversidade amazônica, considerando a imprescindível inter-relação dos conhecimentos tradicionais dos povos da Amazônia com a conservação ambiental.

A hipótese retromencionada impulsionou o desenho dos seguintes objetivos específicos para se alcançar os achados pretendidos: estudar a transnacionalidade; estudar a proteção jurídica dos conhecimentos tradicionais associados à biodiversidade amazônica; analisar os institutos relacionados, como a proposta de criação de um instrumento de regulação transnacional no âmbito do Tratado de Cooperação Amazônico, como uma normatização transnacional, criada por intermédio da conjugação dos interesses comuns dos países amazônicos, os conhecimentos tradicionais associados à biodiversidade amazônica no âmbito da União de Nações Sul-Americanas, o Protocolo de Nagoia e a Lei n. 13.123/2015.

O marco de referência privilegia a construção teórica segundo a qual analisa a possibilidade da criação de elementos para o desenvolvimento de um regime jurídico transnacional sustentável de proteção jurídica dos conhecimentos tradicionais associados à biodiversidade amazônica, desdobra-se por meio de três pontos principais: o primeiro estuda a transnacionalidade e a proteção jurídica dos conhecimentos tradicionais associados à biodiversidade amazônica; o segundo analisa os institutos relacionados, como a proposta de criação de um instrumento de regulação transnacional no âmbito do Tratado de Cooperação Amazônico, como uma normatização transnacional, criada por intermédio da conjugação dos interesses comuns dos países amazônicos, os conhecimentos tradicionais associados à biodiversidade amazônica no âmbito da União de Nações Sul-Americanas, o Protocolo de Nagoia e a Lei n. 13.123/2015; e o terceiro verifica a possibilidade de criação dos elementos para o desenvolvimento de um regime jurídico transnacional sustentável de proteção jurídica dos conhecimentos tradicionais associados à biodiversidade amazônica.

Pelo método de abordagem indutivo, fonte de pesquisa bibliográfica e legal relativa aos conhecimentos tradicionais associados à biodiversidade amazônica serão pesquisadas e confrontadas as partes de um todo para que se possa ter uma visão generalizada. Durante as diversas fases da pesquisa serão utilizadas as técnicas do referente, da categoria, do conceito operacional, do fichamento e com base em documentação indireta será realizada a pesquisa 
bibliográfica.

O trabalho em apreço finda com as conclusões, em que serão apresentados pontos conclusivos abstraídos da pesquisa, a análise e a inferência das reflexões realizadas em relação a possibilidade de criar elementos para o desenvolvimento de um regime transnacional sustentável de proteção jurídica dos conhecimentos tradicionais associados à biodiversidade amazônica.

\section{A PROTEÇÃO JURÍDICA DOS CONHECIMENTOS TRADICIONAIS ASSOCIADOS À BIODIVERSIDADE AMAZÔNICA E A TRANSNACIONALIDADE}

Em Cruz e Bodnar (2009, p. 4) a questão vital ambiental justifica a construção de espaços públicos transnacionais, com a instituição de um Direito Transnacional que transpassaria vários estados nacionais, com capacidade própria de aplicação coercitiva por uma estrutura organizativa transnacional. Agregaria a mesma lógica do Estado Constitucional Moderno, formado a partir de normas jurídicas inter-relacionadas formadoras de um sistema.

Para Cruz e Bodnar (2009, p. 16) o ordenamento jurídico transnacional apresentaria características próprias, derivadas da mesma concepção do Estado Transnacional como organização destinada a atuar em espaço de governança regulatória e de intervenção até agora não organizado politicamente.

O Direito Transnacional e o Estado Transnacional diferem do Estado Constitucional Moderno. Quanto à soberania exercida pelos Estados nacionais e se encontra em estado de obsolescência, a cidadania necessitaria ser exercida em outras bases, em que se privilegiariam a solidariedade e a cooperação entre pessoas, instituição e Estados, em busca da proteção de bens e valores imprescindíveis, assegurando a vida.

Em relação à territorialidade, o Direito Transnacional e o Estado Transnacional, estariam "desterritorializado", não é o espaço estatal nacional, nem o espaço que está acima dele. "Está por entre eles, ou seja, desvinculado da delimitação precisa do âmbito territorial em que o Estado Constitucional Moderno tenta exercer soberania e tenta impor coercitivamente as suas leis" (CRUZ e BODNAR, 2009, p. 15).

O Estado Transnacional seria a superação do Estado Constitucional Moderno, libertando-o da armadilha territorial e soberania. Reconheceria a globalidade e preconizaria a organização do Direito Transnacional pela redefinição e revitalização do político como Estado e como sociedade. É utópica a ideia de uma nova ordem mundial, porém algumas instituições 
internacionais já exercem suas atividades em caráter transnacional, em sentido hegemônico capitalista, diferente do modelo democrático sistematizado por Cruz e Bodnar.

A floresta amazônica é composta por uma diversidade de habitats, paisagens e fisionomias, soma-se a este cenário a grande complexidade hídrica que caracteriza e alimenta sua heterogeneidade. Índios, quilombolas, extrativistas, seringueiros, castanheiros, quebradeiras de coco, ribeirinhos e agricultores familiares fazem parte da população amazônica, habitam terras formalmente reconhecidas como terras indígenas, reservas extrativistas, reservas de desenvolvimento sustentável, terras quilombolas, projetos de assentamento extrativistas, terras devolutas e unidades de conservação.

Trata-se de um desafio a coordenação para manutenção dos diferentes habitats adicionada aos grandes interesses que permeia ações de desenvolvimento regional, econômico ou sustentável para o espaço amazônico, considerando as possíveis formas de convivências e coexistência com a diversidade existente.

Em relação à complexidade da transnacionalidade, é necessário estudar a proteção jurídica dos conhecimentos tradicionais associados (CTAs) à biodiversidade amazônica. Urge substituir o sistema de patentes e a garantia dos direitos de autor, inadequados para proteger as comunidades tradicionais. A conservação da biodiversidade amazônica e dos conhecimentos tradicionais (CTs) exige, necessariamente, o compromisso e a organização da Bolívia, do Brasil, da Colômbia, do Equador, das Guianas, do Peru, do Suriname e da Venezuela.

Em razão da biopirataria e o constante desmatamento da floresta amazônica, que acarreta a perda dos CTs, é importante a integração entre os países amazônicos, preconizada pela Organização do Tratado de Cooperação Amazônica (OTCA) e a integração entre os Estados em vários blocos regionais existentes ao longo do sistema internacional. Destacam as questões culturais, políticas, jurídicas e de soberania.

Durante o século XX as fronteiras nacionais se multiplicaram e se articulou uma nova forma de organização interestatal. A integração dos países amazônicos torna-se de fundamental importância para o enfrentamento das consequências da globalização. Há uma pauta axiológica comum que preconiza sobremaneira a citada integração, qual seja, a conservação da floresta amazônica, compartilhada pelos oito países (Brasil, Venezuela, Guiana, Colômbia, Equador, Peru, Bolívia e Suriname) integrantes do Tratado de Cooperação Amazônico (TCA).

Ampliar esta participação no sistema internacional, não só no âmbito econômico, mas também político, cultural e social; fazem parte do objetivo central dos países envolvidos neste processo de integração regional sul-americano. Há interesse e necessidade de integrar os países amazônicos. Considerando que a Amazônia é constituída como fronteira do capital natural em 
nível global, Becker identifica dois projetos: "o primeiro é um projeto internacional para a Amazônia, e o segundo é o da integração da Amazônia, sul-americana, continental" (BECKER, 2006, p. 74).

O primeiro projeto, principalmente na década de 1980 e 1990, "gerou sugestões mundiais pela soberania compartilhada e o poder de gerenciar a Amazônia, que abalou até o Direito Internacional” (BECKER, 2006, p. 77). O segundo projeto, o da integração da Amazônia sul-americana, trata-se de uma "nova escala para pensar e agir na Amazônia" (BECKER, 2006, p. 78-79).

A importância dessa integração encontra-se respaldada em múltiplas razões, dentre as quais se destacam: o fortalecimento do MERCOSUL; uma presença coletiva e estratégia comum no cenário internacional; e o estabelecimento de projetos comuns para o aproveitamento da biodiversidade e da água.

Existem óbices à integração dos países amazônicos relacionados à cultura (diferenças linguísticas e de tipos de colonialismos), à política (atritos entre os Estados), ao direito (diferenças legislativas) e à soberania (interesses exclusivamente nacionalistas e reforço das fronteiras nacionais).

[...] os movimentos contestatórios na Bolívia, a violência permanente na Colômbia e as tentativas de alterar as regras do jogo de uma democracia formal representativa no Peru e na Venezuela, os movimentos sociais no Brasil e os protestos contra a política fiscal do governo na Argentina, o subcontinente está em efervescência e em Milza (1980); Wendt (1999); Goldstein e Keohane (2003); Lessa (2002); Suppo e Lessa (2007) busca de saídas para os problemas de suas sociedades (RATTNER, 2002, p. $15)$.

A ideia de integração ajuda na solução de alguns problemas enfrentados pelos países sul-americanos. Os países que compõem a região amazônica encontram-se livres de instabilidades geradas por conflitos étnicos e disputas fronteiriças, inexiste luta pela hegemonia da região. Existe uma postura historicamente pacífica entre esses países.

Um dos maiores óbices para a efetivação do processo integracionista diz respeito à eliminação de diferenças legislativas. O Tratado de Assunção preceitua a harmonização do direito como meta a ser atingida. Um dos pressupostos para o sucesso na consolidação e aperfeiçoamento do MERCOSUL é que essas diferenças sejam minimizadas, principalmente as normas que regem a atuação empresarial em cada Estado-membro, com significativo impacto nos seus custos de produção.

A soberania é o óbice mais evidente à integração entre os países amazônicos. Em relação ao MERCOSUL, as Constituições do Paraguai e Argentina admitem a ordem jurídica 
supranacional, ao contrário do Brasil e Uruguai. Embora existam os obstáculos citados, alguns antecedentes podem servir de plataforma para a almejada integração dos países membros do TCA, a saber: os tratados internacionais levados a efeito pelo MERCOSUL e TCA, a criação da Rede latino-americana de Ministério Público Ambiental e a integração estabelecida entre os povos amazônicos.

Baseado na pressão de uso e impacto que as populações exercem sobre o ambiente amazônico e suas relações com o modo como ocupam, exploram e concebem sua relação com a natureza, Lima e Pozzobon desenvolveram um modelo socioambiental de ocupação humana da Amazônia e um modelo das demandas socioambientais para resolver o aumento do grau de sustentabilidade das categorias analisadas.

O elemento mais importante em uma estratégia de desenvolvimento sustentável na Amazônia está na aplicação sistemática da ciência e da tecnologia para o uso e a exploração sustentável de sua biodiversidade, o que supõe atividades empresariais e políticas públicas bem diferentes das que predominam nos dias de hoje (LIMA e POZZOBON, 2005, p. 49).

Os povos tradicionais dos países que compõem a região amazônica desconhecem fronteiras, produzem CTAs à biodiversidade por meio de constante compartilhamento de saberes. Estimulados pela tradição oral da difusão do conhecimento tradicional (CT), pela troca de experiências sobre um mesmo bioma e pela lógica coletiva de intercâmbio de saberes, os diferentes povos da região amazônica geram CTA assemelhado.

As particularidades da Amazônia reclamam por um sistema normativo relacionado à realidade dos povos amazônicos, e, assim, tornar efetiva a proteção ao CT gerado nessa região transnacional. O Direito Transnacional relacionado à questão ambiental agrega a mesma lógica do Estado Constitucional Moderno, formado por normas jurídicas inter-relacionadas que constituem um regime jurídico.

O Direito Transnacional transpassa vários estados nacionais, com capacidade de aplicação coercitiva por estrutura organizativa transnacional, com características próprias, derivadas da concepção do Estado Transnacional, com organização para atuar em espaço de governança regulatória e intervenção. A criação de espaços jurídicos transnacionais, com poderes coercitivos, formulados democraticamente, proporcionará a efetividade da proteção ambiental amazônica e, consequentemente, a proteção aos povos e seus CTs. 


\section{ANÁLISE DOS INSTITUTOS RELACIONADOS}

Considerando o tratamento sustentável dos CTs dos povos da Amazônia, como construir os elementos para o desenvolvimento de um regime transnacional de proteção jurídica dos CTAs à biodiversidade amazônica?

Com o desiderato de compreender a resposta ao questionamento acima formulado, é necessária uma análise crítica dos institutos relacionados ao tratamento sustentável dos CTAs à biodiversidade amazônica, a saber: a proposta de um Tratado de Cooperação amazônico na TRIPs, os CTAs à biodiversidade amazônica no âmbito da UNASUL, o Protocolo de Nagoia, a Lei n. 13.123/2015. Culminará na construção dos elementos para o desenvolvimento de um regime transnacional sustentável de proteção jurídica dos CTAs à biodiversidade amazônica.

Dentre as organizações internacionais sul-americanas que promovem ações conjuntas dos países amazônicos em prol da sustentabilidade do meio ambiente, destacam-se o Mercado Comum do Sul (MERCOSUL) e o Tratado de Cooperação Amazônico (TCA).

O MERCOSUL encontra sérias barreiras de integração entre seus próprios membros, o mesmo não se pode afirmar do TCA, do qual são partes o Brasil, Bolívia, Colômbia, Equador, Guiana, Peru, Suriname e Venezuela. A organização do TCA integra todos os países denominados amazônicos, com exceção da Guiana Francesa.

Em 14 de dezembro de 1998 foi instituída a Organização do Tratado de Cooperação Amazônica (OTCA), organismo internacional para institucionalizar e orientar o processo de cooperação regional dos países amazônicos. $\mathrm{O}$ artigo $1^{\circ}$ do TCA explicita sua completa adesão ao desenvolvimento sustentável da região amazônica, de modo a que essas ações conjuntas produzam resultados equitativos e mutuamente proveitosos, assim como para a preservação do meio ambiente, a conservação e utilização racional dos recursos naturais.

O TCA é um marco jurídico que orienta a cooperação entre os países amazônicos, embora estabeleça a responsabilidade soberana dos países da região na promoção do desenvolvimento sustentável, preconiza a melhoria da qualidade de vida da população amazônica e a defesa de seu patrimônio natural.

Dias (2013) propõe a criação de um Instrumento de Regulação Transnacional (IRT) no âmbito do TCA, como uma normatização transnacional, criada por intermédio da conjugação dos interesses comuns dos países amazônicos: Brasil, Bolívia, Colômbia, Equador, Venezuela, Suriname, Guiana e Peru. A referida autora defende que o IRT poderia vir a se tornar uma possível solução para o alcance da efetiva proteção da Floresta Amazônica e, consequentemente, dos CTs dos povos tradicionais dessa região. 
Na concepção de Dias (2013), a criação do IRT objetivaria harmonizar e positivar o direito ambiental dos países amazônicos, membros do TCA e garantir a aplicação uniforme de suas normas. Trata-se de um instrumento efetivo na resolução dos litígios ambientais no âmbito do Tratado, ou seja, no âmbito dos países amazônicos.

Neste sentido, poderiam utilizar-se do IRT os governos, os particulares, as empresas e as organizações, que possam considerar que direitos foram infringidos por qualquer organização existente no mesmo âmbito. O IRT poderia ser utilizado por todos os países componentes do TCA, com necessidades em comum, sempre visando à proteção dos recursos ambientais amazônicos.

Dias (2013) também propõe haver no IRT previsão específica sobre o julgamento e a imputação de responsabilidades referentes à ocupação da floresta amazônica, bem como a disposição expressa da existência de três etapas para o julgamento de ações, baseadas nos modelos de Cruz e Bodnar.

\footnotetext{
- Constituição dos espaços públicos transnacionais especialmente com base na cooperação, solidariedade e no consenso;

- Capacidade de coerção, como característica fundamental, destinada a garantir a imposição dos direitos e deveres estabelecidos democraticamente a partir do consenso, superando assim uma das principais dificuldades de atuação dos estados no plano externo (CRUZ e BODNAR, 2009, p. 4-5).
}

Destaca-se a influência do modelo levado a efeito por Lima e Pozzobon (2005, p. 70), que trata das demandas socioambientais para promover o aumento do grau de sustentabilidade das categorias analisadas.

Para Benatti (2007, p. 27) a ameaça de internacionalização da Amazônia supõe que os países sul-americanos não se encontram aptos a conservar o meio ambiente amazônico, razão pela qual deveria ser de responsabilidade internacional. Diante dessa ameaça, o argumento sobre a necessidade de integração dos países amazônicos deve ganhar força, inclusive em nível popular. Para Dias (2013) a criação de um espaço jurídico transnacional, por intermédio do IRT no âmbito do TCA, viabilizaria a soberania em nível regional, a efetiva sustentabilidade dos espaços florestais amazônicos, de seus povos e CTs.

A União de Nações Sul-Americanas (UNASUL) é formada pelos países que compõem a América do Sul: Argentina, Bolívia, Brasil, Chile, Colômbia, Equador, Guiana, Paraguai, Peru, Suriname, Uruguai e Venezuela. O Decreto n. 7.667 de 11 de janeiro de 2012 promulgou o Tratado constitutivo que estabeleceu a integração econômica da América do Sul na forma do bloco econômico UNASUL. Os membros do MERCOSUL mais os da CAN uniram-se ao Chile, Guiana e Suriname em uma zona de livre comércio. A entrada em vigor do Tratado 
constitutivo representa um passo fundamental para a consolidação da UNASUL.

Para Garcia (2011, p. 152) a UNASUL objetiva construir um espaço de articulação no âmbito cultural, social, econômico e político entre seus povos. Prioriza o diálogo político, as políticas sociais, a educação, a infraestrutura, o financiamento, o meio ambiente, a paz, a segurança, eliminar a desigualdade socioeconômica, alcançar a inclusão social e a participação cidadã, fortalecer a democracia, reduzir assimetrias no marco do fortalecimento da Soberania e a independência dos Estados.

Entre os objetivos específicos da UNASUL, sobre o tema dos direitos fundamentais difusos transnacionais, destaca-se a proteção da biodiversidade, dos recursos hídricos e dos ecossistemas, bem como a promoção da diversidade cultural, das expressões da memória, dos conhecimentos e saberes dos povos da região para o fortalecimento de suas identidades.

Também se destacam como objetivos específicos da UNASUL: a definição e implementação de políticas e projetos comuns ou complementares de pesquisa, inovação, transferência e produção tecnológica, com vistas a incrementar a capacidade, a sustentabilidade e o desenvolvimento científico e tecnológico próprios; a promoção da cooperação entre as autoridades judiciais dos Estados Membros da UNASUL.

As Constituições dos países sul-americanos são modernos e atuais documentos nos quais já está prevista a proteção dos "novos” Direitos Fundamentais. Para Aguiar de Luque e Lopez Guerra (2009, p. 125) os exemplos são as Constituições da Bolívia, do Equador, da Venezuela, do Brasil e a do Peru. Constituições nas quais estão previstas a proteção do meio ambiente, o do direito do consumidor, o direito da criança e do adolescente, da mulher, do convívio pacífico entre os povos, entre outras demandas transnacionais, além da previsão da formação de uma comunidade latino-americana de nações.

O Protocolo de Nagoia (2011) sobre o acesso a recursos genéticos e a repartição justa e equitativa dos benefícios advindos de sua utilização, foi adotado pelos participantes da Conferência das Partes (COP-10), em 29 de outubro de 2010 em Nagoia, no Japão. Trata-se de um acordo complementar a Convenção sobre Diversidade Biológica (CDB), assinada durante a Rio-92. O Brasil embora signatário do acordo em 2010 se manteve fora das negociações, porque ainda não ratificou o documento, por pressão do agronegócio brasileiro.

Por meio deste Protocolo, fornecedores; como países detentores de grande biodiversidade e usuários de recursos genéticos, por exemplo, empresas farmacêuticas; desfrutarão de maior segurança jurídica e transparência em suas relações, uma vez que o Protocolo estabelece condições mais previsíveis ao acesso de recursos genéticos e garante a repartição dos seus benefícios com quem os forneceu. 
Estas regras criam incentivos para a conservação e o uso sustentável de recursos genéticos e da biodiversidade. As comunidades com CTs deverão ser um dos principais ganhadores desta moldura legal, pois serão remuneradas por empresas que usufruírem dessas capacidades. É lamentável que o Brasil, país com a maior biodiversidade de fauna e flora do planeta, com inúmeras comunidades tradicionais e povos indígenas, não tenha ainda ratificado este importante documento e, desta forma, esteja excluído das discussões oficiais.

A Lei n. 13.123, de 20 de maio de 2015 , regulamenta o inciso II do $\S 1^{\circ}$ e o $\S 4^{\circ}$ do art. 225 da Constituição Federal, o artigo $1^{\circ}$, a alínea "j" do artigo $8^{\circ}$, a alínea "c" do artigo 10, o artigo 15 e os $\S \S 3^{\circ}$ e $4^{\circ}$ do artigo 16 da Convenção sobre Diversidade Biológica, promulgada pelo Decreto n. 2.519, de 16 de março de 1998.

A Lei n. 13.123/2015 revogou a Medida Provisória n. 2.186-16, de 23 de agosto de 2001 e dispõe sobre o acesso ao patrimônio genético, sobre a proteção e o acesso ao CTA e sobre a repartição de benefícios para a conservação e o uso sustentável da biodiversidade. Sanciona condutas e atividades lesivas ao patrimônio genético ou ao CTA.

Segundo determina o $\S 1^{\circ}$ do artigo 10 da referida Lei, qualquer CTA ao patrimônio genético será considerado de natureza coletiva, ainda que apenas um indivíduo de população indígena ou de comunidade fradicional o detenha. De posse da revelação do CT até então velado, a empresa ou laboratório reduz a complexidade das pesquisas necessárias à obtenção de um novo produto útil, tendo, com isso, considerável proveito econômico. O novo produto é patenteado e, por um prazo legal de vinte anos, a empresa ou laboratório se beneficia do que, por esse esforço conjunto, foi acrescido ao conhecimento de toda a sociedade.

O texto da MP n. 2.186-16/01 apresenta vários pontos que mereceriam aprimoramento, para assegurar, de forma ampla, os direitos de povos tradicionais. Todavia, os referidos foram modificados pela Lei n. 13.123/15. Apesar do longo processo de elaboração de anteprojetos de lei na esfera do governo federal, na concepção de Moreira e Conde (2017, p. 179) a nova lei não resultou de um processo amplo e participativo. Não permitiu o efetivo debate e a consulta prévia aos povos e comunidades tradicionais afetados.

A referida Lei criou mecanismos que reduziram a proteção jurídica dos CTs, estabeleceu hipóteses em que o acesso aos CTAs pode efetivar-se sem a exigência do consentimento prévio e informado e sem a obrigação de repartição de benefícios. A Lei n. 13.123/2015 representa inúmeros retrocessos em relação à proteção dos CTAs. 


\section{OS ELEMENTOS PARA O DESENVOLVIMENTO DE UM REGIME TRANSNACIONAL SUSTENTÁVEL DE PROTEÇÃO JURÍDICA DOS CONHECIMENTOS TRADICIONAIS ASSOCIADOS À BIODIVERSIDADE AMAZÔNICA}

Considerando a imprescindível inter-relação dos CTs dos povos da Amazônia com a conservação ambiental, o estudo do tratamento sustentável dos CTAs à biodiversidade amazônica possibilitou a construção dos elementos para o desenvolvimento de um regime transnacional de proteção jurídica. Trata-se da substituição do sistema de patentes, bem como o sistema de garantia dos direitos de utor, inadequados para proteger os povos tradicionais. É limitada a perspectiva que oferecem os direitos nacionais e internacionais em vigor relacionados aos CTAs à biodiversidade amazônica.

A floresta amazônica está inserida além do Brasil, em territórios de outros países sulamericanos como Bolívia, Colômbia, Equador, Guiana, Guiana Francesa, Peru, Suriname e Venezuela, portanto, sua conservação exige, necessariamente, o compromisso e a organização de todos esses países. Os acordos já existentes entre os países amazônicos ratificam a possibilidade de construção dos elementos defendidos. Objetivou-se investigar, com o propósito de revelar, a possibilidade da construção de elementos para o desenvolvimento de um regime transnacional de proteção jurídica dos CTAs à biodiversidade amazônica.

A efetividade da proteção jurídica dos CTs está relacionada com a sustentabilidade, a capacidade de uma população ocupar uma determinada área e explorar seus recursos naturais sem ameaçar, ao longo do tempo, a integridade ecológica do meio ambiente. Sustentabilidade deve ser um projeto de civilização revolucionário e estratégico de futuro, pautado na consciência crítica sobre a finitude dos bens ambientais e na responsabilidade global e solidária pela proteção, defesa e melhora contínua de toda a comunidade de vida e dos elementos que the dão sustentação e viabilidade.

A partir da ampla aceitação do princípio da sustentabilidade em âmbito mundial e o avanço dos estudos, os povos tradicionais amazônicos, antes invisíveis, passam a ser consideradas como verdadeiros protagonistas da sustentabilidade. Baseado na pressão do uso e impacto que as populações exercem sobre o ambiente amazônico e suas relações com o modo como ocupam, exploram e concebem sua relação com a natureza, desenvolveram um modelo socioambiental da ocupação humana da Amazônia e um modelo das demandas socioambientais para resolver o aumento do grau de sustentabilidade das categorias analisadas.

Ao contrário dos povos indígenas, os latifúndios recentes e os exploradores itinerantes 
apresentam uma cultura ecológica predatória e apresentam baixos índices da dimensão ambiental da sustentabilidade. Na busca pela dimensão ambiental da sustentabilidade amazônica e a proteção dos CTs encontra-se desmatamentos e violência entre extrativistas e latifundiários.

A conservação do meio ambiente é uma condição para o desenvolvimento. Representa uma nova ordem mundial que pode suscitar a dimensão ambiental da sustentabilidade amazônica, ou seja, mediante a transnacionalidade.

A instituição de um Direito Transnacional relacionado à questão vital ambiental agrega a mesma lógica do Estado Constitucional Moderno, formado por normas jurídicas interrelacionadas formadoras de um sistema. O Direito Transnacional transpassaria vários estados nacionais, com capacidade própria de aplicação coercitiva por uma estrutura organizativa transnacional.

O ordenamento jurídico transnacional apresentaria características próprias, derivadas da mesma concepção do Estado Transnacional como organização destinada a atuar em espaço de governança regulatória e de intervenção até agora não organizado politicamente.

Propõe-se alguns elementos para o desenvolvimento de um regime transnacional sustentável de proteção jurídica dos CTAs à biodiversidade amazônica, no sentido de se tornar uma possível solução para o alcance da efetiva proteção da região amazônica e, consequentemente, dos CTs dos povos tradicionais dessa região.

Para a construção dos elementos para o desenvolvimento de um regime transnacional sustentável de proteção jurídica dos CTAs à biodiversidade amazônica, urge considerar os beneficiários e titulares da proteção, o objeto da proteção, o conteúdo dos direitos, os objetivos perseguidos, os modos de aquisição dos direitos, a duração, os mecanismos de proteção desses direitos e os requisitos da proteção.

Representam elementos para o desenvolvimento de um regime transnacional sustentável de proteção jurídica dos CTAs à biodiversidade amazônica: sistemas diversos para conhecimentos diversos, dinâmicos, complexos, criados dentro de um contexto com normas e práticas consuetudinárias.

É necessária a adoção de medidas para a preservação e salvaguarda dos CTs e o estabelecimento de mecanismos que protejam esses conhecimentos de utilização não utilizada ou indevida com fins de ofender os conhecimentos, inovações e práticas tradicionais. Um sistema que busque uma proteção eficaz, tanto positiva como preventiva.

O pluralismo fundado em uma democracia expressa o reconhecimento dos valores coletivos materializados na dimensão cultural de cada povo. Em uma sociedade multicultural o 
sistema jurídico deve ser agregado um conteúdo material substantivo às normas para que efetivamente estejam a serviço da justiça. Desta forma, o direito será efetivamente instrumento de transformação social, por fomentar cooperação e solidariedade.

Um projeto de futuro com sustentabilidade busca a melhoria das condições sociais das populações socialmente mais fragilizadas. O objeto de proteção é o conhecimento, as inovações e práticas que integram o patrimônio cultural material e imaterial das comunidades indígenas e locais.

Um regime de proteção jurídica deve partir da premissa que uma relação entre partes desiguais deve conter mecanismos de freios e contrapesos para equilibrar a relação contratual. Desta forma, é fundamental a inversão do ônus da prova em favor dos credores dos CTs, facilitando a sua defesa. É necessário estabelecer uma Entidade de Gestão que participe das decisões sobre as normas e políticas relacionadas às comunidades Tradicionais.

Os fundos compensatórios constituem importantes instrumentos jurídicos para garantir que os povos tradicionais amazônicos possam concordar com recursos econômicos para o desenvolvimento de projetos de conservação, desenvolvimento para a proteção dos conhecimentos, inovações e práticas tradicionais.

O registro voluntário pelos possuidores pode ser um instrumento útil na proteção e especialmente na preservação dos mesmos. Nas bases de dados os registros dos CTs somente podem ser considerados como um enfoque para a proteção dos mesmos, mas não como requisito para proteção e menos ainda para o reconhecimento dos direitos dos povos tradicionais.

Garantir os direitos dos povos tradicionais quando seus conhecimentos são utilizados pela indústria biotecnológica é uma proteção complexa, eis a dificuldade de identificação do CT original e o produto industrializado, o preconceito epistêmico e a dificuldade de transitarse entre as normas nacionais e internacionais sobre o tema.

Destaca-se o papel do direito ambiental para a sustentabilidade da floresta amazônica, espaço que não conhece fronteiras, razão pela qual se adotou a visão transnacional do Direito Ambiental. A sustentabilidade é essencial para manter os modos de vida dos povos tradicionais, sendo necessário compatibilizar a proteção ambiental com o avanço econômico e a justiça social.

As demandas socioambientais de uma sociedade de risco exigem respostas que a soberania não é capaz de oferecer e o mercado é outro fator de fragmentação, sendo necessário desenvolver um Direito Transnacional. No contexto da Amazônia se propõe a estruturação do sistema de Direito Transnacional por meio da construção de elementos para o desenvolvimento de um regime transnacional sustentável de proteção jurídica dos CTAs à biodiversidade 
amazônica. Objetiva-se uma conjugação dos interesses comuns dos países que integram a região amazônica.

Para dar exequibilidade a este regime, de modo democrático deve ocorrer etapas de ampla participação, promovendo soberania local e enfrentamento da colonialidade, garantindo a sustentabilidade e a manutenção de seus povos tradicionais, seus modos de vida e conhecimentos. O referido regime servirá para normatizar a sustentabilidade dos ambientes florestais amazônicos, por meio da conjugação dos interesses comuns dos países amazônicos. Sua criação objetiva harmonizar e positivar o Direito Ambiental dos países amazônicos, garantindo a aplicação uniforme de suas normas e servindo de instrumento efetivo na resolução dos litígios ambientais.

\section{CONCLUSÃO}

Em função da problemática e da hipótese, o objetivo geral do trabalho consiste em analisar a possibilidade de criar elementos para o desenvolvimento de um regime transnacional sustentável de proteção jurídica dos conhecimentos tradicionais associados à biodiversidade amazônica, considerando a imprescindível inter-relação dos conhecimentos tradicionais dos povos da Amazônia com a conservação ambiental.

O trabalho em testilha estudou a transnacionalidade e a proteção jurídica dos conhecimentos tradicionais associados à biodiversidade amazônica. Pela amplitude do tema e a necessidade de melhorar a proteção jurídica destes importantes conhecimentos, requereu um esquema conceitual que lhe conferiu um instrumental teórico suficientemente articulado para a sua problemática. Foi utilizado o método indutivo e nas diversas fases da pesquisa foram acionadas as técnicas do referente, da categoria, do conceito operacional, da pesquisa bibliográfica e do fichamento.

O trabalho evidenciou a necessidade de um tratamento transnacional sustentável aos conhecimentos tradicionais associados à biodiversidade nos países que integram a região amazônica. O aludido problema concentrou seus esforços na busca de substituir o sistema de patentes, bem como o sistema de garantia dos direitos de autor, inadequados para proteger as comunidades tradicionais. Com vistas a esse fim, percorreu-se, do ponto de vista do marco de referência, a bibliografia de relevância já tornada pública em relação ao tema de estudo.

O equacionamento do problema suscitou na hipótese de que a floresta amazônica está inserida além do Brasil, em territórios de outros países sul-americanos como Suriname, Venezuela, Guianas, Colômbia, Equador, Peru e Bolívia, portanto, sua conservação exige, 
necessariamente, o compromisso e a organização de todos esses países.

O presente trabalho atingiu o objetivo geral que foi analisar a possibilidade de criar elementos para o desenvolvimento de um regime transnacional sustentável de proteção jurídica dos conhecimentos tradicionais associados à biodiversidade amazônica, considerando a imprescindível inter-relação dos conhecimentos tradicionais dos povos da Amazônia com a conservação ambiental.

Desta forma, o trabalho cumpriu os objetivos específicos propostos e alcançou os achados pretendidos, a saber: estudou a transnacionalidade; estudou a proteção jurídica dos conhecimentos tradicionais associados à biodiversidade amazônica; analisou os institutos relacionados, como a proposta de criação de um instrumento de regulação transnacional no âmbito do Tratado de Cooperação Amazônico, como uma normatização transnacional, criada por intermédio da conjugação dos interesses comuns dos países amazônicos, os conhecimentos tradicionais associados à biodiversidade amazônica no âmbito da União de Nações SulAmericanas, o Protocolo de Nagoia e a Lei n. 13.123/2015.

\section{REFERÊNCIAS}

AGUIAR DE LUQUE, Luis; LOPEZ GUERRA, Luis. Las Constituciones de Iberoamérica. 2.ed. Madrid: Centro de Estudios Políticos e Constitucionales, 2009.

BECKER, Bertha Koiffmann. Amazônia: geopolítica na virada do III milênio. Rio de Janeiro: Garamond, 2006.

BENATTI, José Heder. Internacionalização da Amazônia e a questão ambiental: o direito das populações tradicionais e indígenas à terra. Revista Amazônia Legal de estudos sóciojurídico-ambientais. Cuiabá, ano 1, n. 1, p. 23-39, jan./jun. 2007. Disponível em: <http:// www.avesmarinhas.com.br/Internacionaliza\%C3\%A7\%C3\%A3o\%20da\%20Amaz\%C3\%B4n ia\%20e\%20a\%20quest\%C3\%A3o\%20ambiental.pdf>. Acesso em: 24 jul. 2019.

CRUZ, Paulo Márcio; BODNAR, Zenildo. A transnacionalidade e a emergência do estado e do direito transnacionais. In: Direito e transnacionalidade. CRUZ, Paulo Márcio; STELZER, Joana (Orgs.). Curitiba: Juruá, 2009.

DIAS, Mônica Nazaré Picanço. A proteção jurídica transnacional dos conhecimentos tradicionais dos povos amazônicos. 205 f. Tese (Doutorado). Curso de Doutorado em Ciência Jurídica, Universidade do Vale do Itajaí, Santa Catarina, 2013.

GARCIA, Marcos Leite. "Novos" Direitos Fundamentais, trançsnacionalidade e UNASUL: desafios para o século XXI. In: CADEMARTORI, Daniela; CADEMARTORI, Sérgio; MORAES, Germana de Oliveira; COELHO, Raquel. A construção jurídica da UNASUL, p. 141-183. Florianópolis-SC. Fundação José Arthur Boiteux/Editora da UFSC, 2011.

BRASIL. Lei n. 13.123, de 20 de maio de 2015. Disponível em: 
<http://www.planalto.gov.br/ccivil_03/_Ato2015-2018/2015/Lei/L13123.htm>. Acesso em: 15 jul. 2019.

LIMA, Deborah; POZZOBON, Jorge. Amazônia socioambiental. Sustentabilidade ecológica e diversidade social, v. 19, n. 54. São Paulo, mai./ago., 2005. Disponível em:<http://www. scielo.br/scielo.php?pid= S0103-142005000200004\&script=sci_arttext $>$. Acesso em: 10 jul. 2019.

MOREIRA, Eliane Cristina Pinto; CONDE, Leandro Barbalho. A Lei n. 13.123/2015 e o Retrocesso na Proteção dos Conhecimentos Tradicionais. Veredas do Direito, Belo Horizonte, v. 14, n. 29, p. 175-205, mai./ago. 2017. Disponível em: <http://www.domhelder. edu.br/revista/index.php/veredas/ article/view/1017>. Acesso em: 15 jul. 2019.

Nagoya Protocolo on access to genetic resources and the fair and equitable sharing of benefits arising from their utilization to the Convention on Biological Diversity: text and annex. Secretariat of the Convention on Biological Diversity Montreal. Montreal, Quebec, Canadá: Convention on Biological Diversity United Nations, 2011. Disponível em: <https://www.cbd.int/abs/doc/ protocol/nagoya-protocol-en.pdf>. Acesso em: 18 jul. 2019.

RATTNER, Henrique. O futuro incerto dos países sul-americanos. São Paulo: Universidade de São Paulo, 2002. 